\title{
A Model for Interprofessional Health Disparities Education: Student-Led Curriculum on Chronic Hepatitis B Infection
}

\author{
Leslie C. Sheu, $B A^{7}$, Brian C. Toy, BS ${ }^{7}$, Emanuel Kwahk, BS ${ }^{2}$, Albert Yu, MD, MPH, MBA ${ }^{3}$, \\ Joshua Adler, $\mathrm{MD}^{4}$, and Cindy J. Lai, MD ${ }^{4}$
}

'School of Medicine, University of California, San Francisco, CA, USA; ${ }^{2}$ School of Pharmacy, University of California, San Francisco, CA, USA; ${ }^{3}$ San Francisco Department of Public Health and Department of Family and Community Medicine, University of California, San Francisco, CA, USA; ${ }^{4}$ Department of Medicine, University of California, San Francisco, CA, USA.

BACKGROUND: Although health disparities are commonly addressed in preclinical didactic curricula, direct patient care activities with affected communities are more limited.

PURPOSE: To address this problem, health professional students designed a preclinical service-learning curriculum on hepatitis B viral (HBV) infection, a major health disparity affecting the Asian/Pacific Islander (API) population, integrating lectures, skills training, and direct patient care at student-run clinics.

SETTING: An urban health professions campus.

METHODS: Medical and other health professional students at University of California, San Francisco, organized a preclinical didactic and experiential elective, and established two monthly clinics offering HBV screening, vaccination, and education to the community.

RESULTS: Between 2004 and 2009, 477 students enrolled in the student-led HBV curriculum. Since the clinics' inception in 2007, 804 patients have been screened for chronic HBV; $87 \%$ were API immigrants, $63 \%$ had limited English proficiency, and 46\% were uninsured. Serologically, 10\% were found to be chronic HBV carriers, $44 \%$ were susceptible to $\mathrm{HBV}$, and $46 \%$ were immune.

DISCUSSION: Our student-led didactic and experiential elective can serve as an interprofessional curricular model for learning about specific health disparities while providing important services to the local community.

KEY WORDS: medical education-undergraduate; underserved populations; medical education-curriculum development/evaluation; disparities; community based interventions; student-run clinic.

Preliminary work was presented at a poster session at the Center for Disease Control and Prevention National Immunization Conference in March 2009 and at an abstract session at the Society of General Internal Medicine Disparities Education Symposium at the Association of American Medical Colleges Annual Meeting in November 2009.

Financial support was received through direct in-kind support from University of California, San Francisco Mount Zion Medical Center and San Francisco Department of Public Health Chinatown Public Health Center, intramural funding from the Mount Zion Health Fund, as well as through extramural funding from the Association of American Medical Colleges, American Liver Foundation, and Asian American Network for Cancer Awareness, Research and Training.
J Gen Intern Med 25(Suppl 2):140-5

DOI: $10.1007 / \mathrm{s} 11606-009-1234-\mathrm{Z}$

(C) Society of General Internal Medicine 2010

\section{BACKGROUND}

The Institute of Medicine and Liaison Committee on Medical Education have called attention to the shortage of medical curricula that address health disparities ${ }^{1,2}$. The Society of General Internal Medicine Health Disparities Task Force has recommended the inclusion of curricular content focused on eliminating inequities in heath care quality through health disparities education ${ }^{3}$. Current preclinical curricula on health disparities are primarily lecture-based, offering students little opportunity to connect with affected populations or to appreciate the unique challenges of implementing community interventions ${ }^{4-6}$. One strategy to integrate experiential learning about health disparities into preclinical curricula is through service-learning, an educational model that combines direct community service with formal learning objectives and student reflection ${ }^{7-12}$. Such service-learning curricula have been widely implemented in nursing, dentistry, and pharmacy schools, and are becoming more popular in medical schools ${ }^{7-9}$. At Cook County Hospital, faculty and community members developed a successful hospitalcommunity partnership to teach interns about health disparities, which received positive evaluations from both community teachers and residents ${ }^{13}$.

While most health disparities curricula are developed and implemented by faculty, health professional students at our campus led the creation of an interprofessional service-learning curriculum focused on a local health disparity, chronic hepatitis B viral (HBV) infection. Chronic HBV affects one in ten Asian/ Pacific Islanders (APIs), compared with 1 in 1,000 in the general population, and is responsible for up to a 13-fold higher mortality rate from liver cancer in APIs compared to whites ${ }^{14,15}$. Chronic HBV has particular salience in San Francisco, where $33 \%$ of the city's population self-identifies as API, compared to $5 \%$ nationally ${ }^{16}$. In 2007, a coalition of community agencies, including the San Francisco Department of Public Health (DPH), launched "SF Hep B Free," a citywide campaign to screen all API residents for $\mathrm{HBV}$ and to make low-cost vaccines available to those at risk.

Although HBV is a major health disparity affecting the API community, recent reports found that both physicians and API 
patients demonstrated low awareness and knowledge about HBV screening, transmission, and epidemiology ${ }^{17,18}$. The CDC recommends screening populations with a prevalence of hepatitis $\mathrm{B}$ infection greater than $2 \%$, but screening rates in at-risk API populations remain low ${ }^{14}$.

The confluence of demographics, municipal priority, and national medical education recommendations provided a unique opportunity to develop a focused health disparity curriculum at University of California, San Francisco (UCSF). In this report, we describe the San Francisco Hepatitis B Collaborative (SFHBC) service-learning curriculum for preclinical health professional students, which may serve as a model for designing and structuring other interprofessional preclinical curricula on health disparities.

\section{METHODS}

\section{Overview of Program}

SFHBC is a student-led organization whose roots trace back to 2003 (Fig. 1), when ten third-year medical students at UCSF completed a project designed to improve HBV screening of API patients at the Family Medicine practice. A subset of these students, in conjunction with a faculty advisor, formed SFHBC in 2004. They worked closely with faculty in the Departments of Family and Community Medicine and Internal Medicine, establishing a didactic elective on HBV and expanding student involvement to include preclinical students from the Schools of Nursing, Pharmacy, and Dentistry. In 2007, SFHBC established two permanent monthly clinics, located at UCSF Mount Zion Medical Center and at Chinatown Public Health Center, the latter affiliated with the DPH. These permanent clinics enabled SFHBC to provide free HBV screenings, free to low-cost HBV vaccinations, and for those with chronic HBV infection, follow-up visits for education and specialty clinic referrals.

\section{The SFHBC HBV Health Disparity Curriculum}

The SFHBC curriculum, initiated by preclinical students from different health professional schools and designed for their peers, consisted of three components: a didactic elective, clinical skills elective, and clinical practicum (Fig. 2). The goals of the curriculum were two-fold: (1) to address the HBV health disparity facing the API community through direct clinical interventions and (2) to increase awareness about the HBV health disparity among health professional students.

Student participation in the curriculum was voluntary and offered through all preclinical health professional schools those who enrolled received course credit. Students could either enroll in the didactic elective alone for one course credit or participate in all three aspects of the curriculum for two course credits.

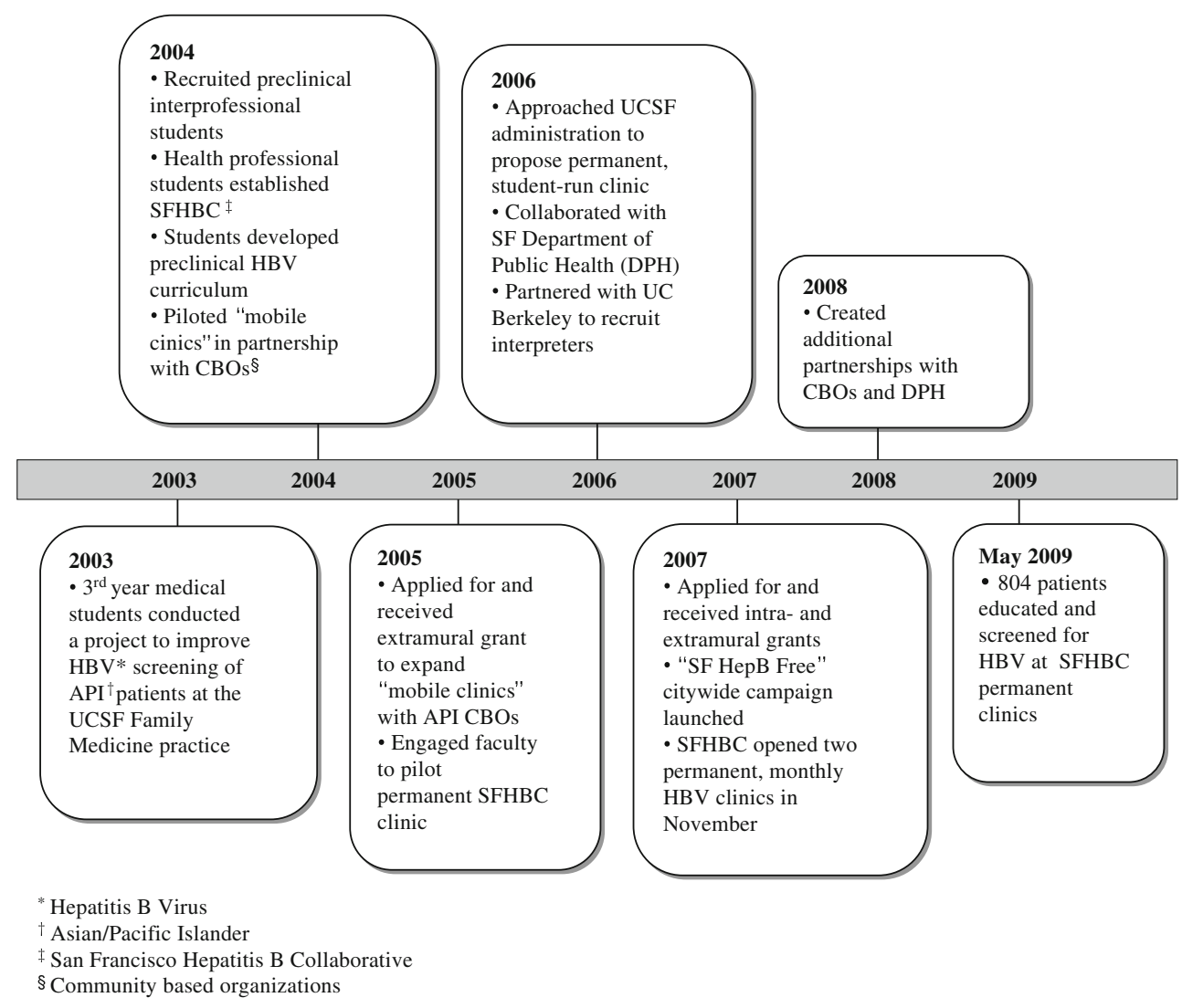

Figure 1. Development and implementation of $\mathrm{HBV}^{*}$ health disparity curriculum. 


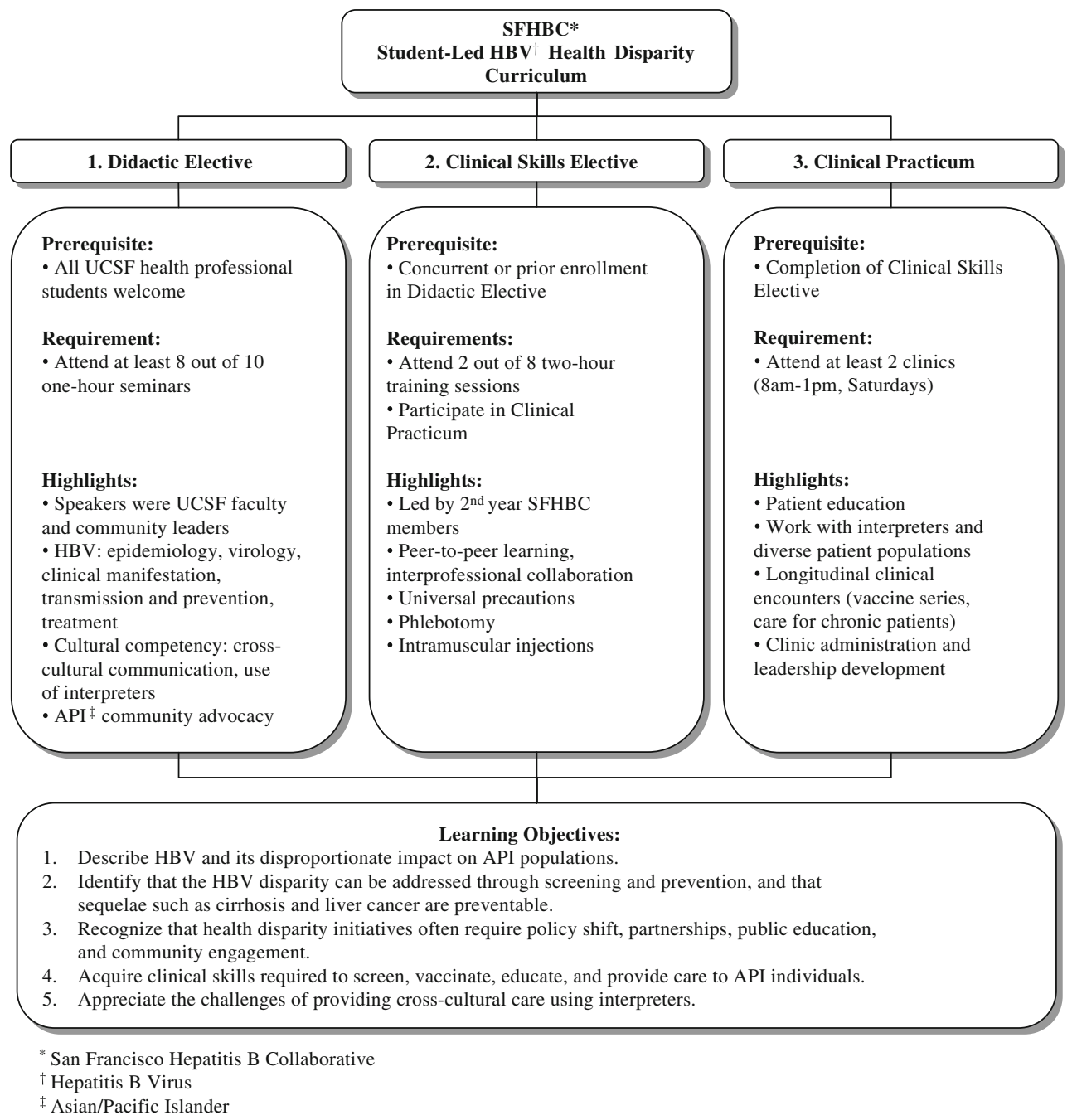

Figure 2. The SFHBC ${ }^{*}$ student-led $\mathrm{HBV}^{\dagger}$ health disparity curriculum.

\section{Community Outreach and Culturally Competent Care}

Community outreach for the clinics was targeted toward the at-risk API population. Patients were recruited through language-concordant media, word of mouth, e-mail lists, community presentations, and provider referrals; we also received referrals through the DPH's citywide campaign to eliminate HBV. To address language barriers and provide culturally competent care, student board members established a partnership with UC Berkeley, where undergraduates fluent in API languages (Chinese, Vietnamese, Korean, Japanese, and Tagalog) were recruited and trained to serve as interpreters. In addition, patient education materials were made available in these languages, and language-concordant telephone scripts were used for patient follow-up reminders.

\section{Roles of Students and Faculty}

Prior to establishing permanent clinics, students spent several months writing grants and working with key faculty advisors.
Students received intra- and extramural grants to start the two permanent clinics, with additional support through in-kind donations from UCSF Medical Center and the DPH. This financial support enabled SFHBC to provide free screenings to all patients and free or low-cost vaccinations to HBVsusceptible patients.

Recognizing that successful volunteer recruitment and community engagement require sustained effort, funding, and partnerships, students in SFHBC created an interprofessional leadership advisory board with three interconnected branches: internal affairs, clinic operations, and outreach. The board consisted of 15 to 25 students who met weekly to discuss upcoming course logistics, clinics, outreach events, and organizational issues. Student board membership changed yearly as students advanced through school. Leadership was transitioned to first-year students in the winter quarter of each academic year, providing overlap between outgoing and incoming board members.

Data were collected on student participation rates, patient demographics, test results, and vaccine use at each clinic. The Institutional Review Board at UCSF approved this study. 


\section{RESULTS}

\section{Educational Outcomes}

Between 2004 and 2009, 477 students enrolled in the SFHBC didactic elective, consisting of 54\% pharmacy, $24 \%$ medicine, $17 \%$ nursing, and 5\% dental students. Ninety-three percent were first-year students, with the remainder being in their second or third years. Over three-quarters $(78 \%)$ of students also enrolled in the clinical skills elective and participated in the clinical practicum. Annual enrollment in the SFHBC elective steadily increased from 67 students in 2004-05 to 142 students in 2008-09.

Between October 2008 and May 2009, students participated in an average of 1.89 clinics (SD \pm 1.32 ), with medical students volunteering twice as often as students from other schools ( $\bar{x}=4.1$ clinics, $P=0.004$ ). Three-quarters of participants were female and two-thirds identified themselves as API. Of those who self-identified as API, $65 \%$ reported being fluent in an API language and $32 \%$ were born in Asia.

\section{Clinical Outcomes}

From November 2007 to May 2009, SFHBC educated and screened 804 patients. Fifty-eight percent of patients were screened at UCSF Mount Zion Medical Center, and 42\% were screened at Chinatown Public Health Center. The average age was $49(\mathrm{SD} \pm 16)$ and $55 \%$ were female. Eighty-seven percent of our patients were first-generation API immigrants, hailing from 14 different countries, with the majority from China, Vietnam, Hong Kong, Japan, Burma, Taiwan, and Korea. Fifty-three percent had immigrated within the last 15 years, and 63\% reported limited English proficiency. Interpreters speaking nine different languages and dialects were provided in over 1,229 distinct encounters at the two clinic sites. From March to May 2009, when patients began to report their income, $55 \%$ of patients reported an annual household income less than $\$ 25,000$, well below the median household income in San Francisco of $\$ 71,957^{19}$. Fortysix percent of patients were uninsured.

Serologic testing revealed that $10 \%$ of patients were HBVinfected [positive for hepatitis B surface antigen (HBsAg)], 44\% were $\mathrm{HBV}$-susceptible [negative for both HBsAg and hepatitis B surface antibody (anti-HBs)], and 46\% were HBV-immune (HBsAg-negative and anti-HBs-positive). HBV-susceptible patients were encouraged to get vaccinated. Ninety percent of these patients completed or were on track to complete the three-shot vaccination series.

\section{DISCUSSION}

The disparity in HBV prevalence between APIs and the general population, coupled with San Francisco's demographics, presented an opportunity for students to create a preclinical curriculum that simultaneously: (1) provided a needed service to the surrounding community and (2) educated health professional students about engaging in community advocacy and addressing health disparities.

There is a growing emphasis in health professional schools to incorporate community-based and patient care experiences early into the preclinical curriculum ${ }^{20,21}$. Creating a structured, service-learning elective allowed our students to work with an underserved community soon after entering graduate school. Health professional students often come from backgrounds where volunteerism is valued and expected, especially in settings of helping vulnerable persons, and many students are eager for direct patient contact early in their health professional programs ${ }^{22}$. In a survey of 49 medical schools with one or more student-run clinics, the most commonly cited reasons for student volunteerism included opportunities to serve the poor, interact with patients, and learn clinical skills $^{23}$. Our curriculum also allowed students to gain an early understanding of clinic operations and to take an active role in a larger citywide public health intervention addressing a health disparity.

Our outreach efforts, using language-concordant methods, successfully reached our target population, as the majority of our patients were API immigrants with limited English proficiency and low socioeconomic status. Given these language and financial barriers, such patients often suffer from poor access to care and subsequent poor health outcomes ${ }^{24-27}$. In fact, limited English proficiency has been suggested as the largest barrier to successful management of chronic HBV infection-a potentially treatable condition-ultimately putting patients at risk for complications of liver disease and furthermore posing a potential public health hazard for disease transmission $^{24,28,29}$.

Community-based outreach efforts and screenings have been shown to be effective strategies to promote HBV knowledge and awareness among API populations ${ }^{15,30,31}$. Our 90\% completion rate for the three-shot HBV vaccination series was higher than reported in the literature ${ }^{32,33}$. This success may be attributed to intensive patient education during initial screening encounters and return visits, followup phone calls to patients who missed return visits, as well as culturally appropriate and language-concordant patient materials and telephone scripts, which have been shown to improve vaccine compliance rates ${ }^{34-36}$. A major challenge experienced by other community HBV screening programs has been ensuring follow-up care, particularly surveillance for disease progression and initiation of antiviral treatments for HBV-infected individuals ${ }^{37}$. We addressed this issue largely through our partnership with the community-based Chinatown Public Health Center, where we provided HBVinfected individuals with initial follow-up and referrals to specialty clinics.

The majority of students were of API descent, mirroring the ethnic makeup of the patients. This inherent interest of API students to learn about and address disparities within their own ethnic community is important, as race-concordance between patients and providers has been shown to improve health care outcomes ${ }^{38-41}$. This may partially explain the high proportion of student participants from the pharmacy school, which has a high enrollment of API students. Pharmacy students were likely also drawn to the elective as it was one of their few opportunities for sustained patient interaction and involvement in clinic operations. Preclinical medical students had many competing electives from which they could choose, including those with direct patient contact, and thus, it is promising that so many students were interested in this elective.

A unique aspect of the curriculum was its emphasis on interprofessional collaboration in the clinics and on the leadership board. During clinics, we attempted to create 
interprofessional pairs for all aspects of patient care, allowing students from different health professions to learn from one another. Ultimately, we believe this allowed for productive teamwork, development of mutual respect, and shared learning among students from different health professional backgrounds, outcomes which have been borne out in other interprofessional clinical settings ${ }^{42-44}$.

While our curriculum was successful in its broad scope of community outreach and student involvement, we faced challenges in its development and implementation. Finding permanent clinic sites for the clinical practicum took 3 years, requiring faculty, institutional, and community support, studentwritten grants, and student persistence. Although our initial grants enabled us to provide free screening and free or low-cost vaccinations to all of our patients, long-term sustainability of our clinics will require additional funding. In terms of quality of care, although enrolled students participated in two clinical skills training sessions, all but a few were novices at performing phlebotomy and intramuscular injections. Therefore, balancing student learning and patient discomfort, an ethical dilemma of many student-run clinics, required vigilance from student coordinators and clinic preceptors ${ }^{45}$. For clinical procedures, we paired students with different experience levels, hoping to enhance both student and patient comfort. Finally, ensuring a consistent flow of patients into each monthly clinic required regular promotion within the API community, which we were able to do successfully through partnerships with community-based organizations and the city's DPH.

A limitation of this curriculum is that during the first year of the permanent clinics, we did not formally survey students or patients about their experiences, although students conducted volunteer debriefings after each clinic. We have since begun to evaluate the impact of the curriculum on students' knowledge and attitudes toward health disparities and interprofessional education, and to implement a formal reflective component into our service-learning curriculum. We will also evaluate the effect of our clinics on patients' knowledge and their attitudes toward student-run clinics.

The challenges to developing an interprofessional servicelearning curriculum were not insurmountable and are akin to common challenges reported by other student-run free clinics throughout the country-each requires careful planning, preparation, faculty involvement, and community and institutional support ${ }^{46,47}$. Student engagement was critical to overcoming many of our challenges, as students' collaborative energy, enthusiasm, and perseverance resulted in fruitful outcomes, such as bringing together faculty and community groups and securing funding. Similar to how the voluntary, student-led nature of service-learning programs at Rush University were fundamental to their success over the past 2 decades, we believe our integrated didactic and experiential service-learning curriculum will continue to flourish under student leadership ${ }^{12}$. Our successes support the idea that engaging preclinical students in health screenings, outreach, and advocacy is one powerful way to reduce health disparities while training students to address them ${ }^{11}$.

Acknowledgements: The authors would like to thank: (1) UCSF Mount Zion Medical Center and San Francisco Department of Public Health Chinatown Public Health Center for their direct in-kind support; (2) the Association of American Medical Colleges, American
Liver Foundation, and Asian American Network for Cancer Awareness, Research and Training for extramural funding; (3) UCSF staff and faculty preceptors, UCSF student volunteers, and UC Berkeley volunteer interpreters for their commitment to the San Francisco Hepatitis B Collaborative; (4) Gladys Morazan, Katie Morris, and Roy Johnston for their continued administrative support.

Conflict of Interest Statement: None of the authors have any conflicts of interest.

Corresponding Author: Leslie C. Sheu, BA; School of Medicine, University of California, San Francisco, CA, USA (e-mail: leslie. sheu@ucsf.edu).

\section{REFERENCES}

1. Institute of Medicine. Unequal Treatment: Confronting Racial and Ethnic Disparities in Health Care. Washington, DC: National Academies Press; 2002.

2. Functions and Structure of a Medical School: Standards for Accreditation of Medical Education Programs Leading to the M.D. Degree. Updated June 2008. Available at www.lcme.org. Accessed December 14, 2009.

3. Smith W, Betancourt JR, Wynia MK, et al. Recommendations for teaching about racial and ethnic disparities in health and health care. Ann Intern Med. 2007;147(9):654-65.

4. Flores G, Gee D, Kastner B. The teaching of cultural issues in US and Canadian medical schools. Acad Med. 2000;75:451-5.

5. Chheda S, Hemmer PA, Durning S. Teaching about racial/ethnic health disparities: a national survey of clerkship directors in internal medicine. Teach Learn Med. 2009;21(2):127-30.

6. Tervalon M, Murray-Garcia J. Cultural humility versus cultural competence: a critical distinction in defining physician training outcomes in multicultural education. J Health Care Poor Underserved. 1998;9(2):117-25.

7. Hood JG. Service-learning in dental education: meeting needs and challenges. J Dent Educ. 2006;73(4):454-63.

8. Brown B, Heaton PC, Wall A. A service-learning elective to promote enhanced understanding of civic, cultural, and social issues and health disparities in pharmacy. Am J Pharm Educ. 2007;71(1):9.

9. Elam CL, Sauer MJ, Stratton TD, et al. Service learning in the medical curriculum: developing and evaluating an elective experience. Teach Learn Med. 2003;15(3):194-203.

10. Seifer S, Murtha S, Connor K. Service learning in health professional education: barriers, facilitators, and strategies for success. In: Raybuck J, eds. Expanding Boundaries: Service and Learning, 1. Washington, DC: Corporation for National Service; 1996:36.

11. Mays VM, Ly L, Allen E, Young S. Engaging student health organizations in reducing health disparities in underserved communities through volunteerism: developing a student health corps. J Health Care Poor Underserved. 2009;20(3):914-28.

12. Eckenfels EJ. The purpose of service learning. Fam Med. 2009;41 (9):659-62.

13. Jacobs EA, Kohrman C, Lemon M, Vickers DL. Teaching physiciansin-training to address racial disparities in health: a hospital-community partnership. Public Health Rep. 2003;118(4):349-56.

14. Weinbaum CM, Williams I, Mast EE, et al. Recommendations for identification and public health management of persons with chronic hepatitis B virus infection. CDC MMWR 2008;(RR08):1-20.

15. Juon H, Strong C, Oh TH, Castillo T, Tsai G, Oh LD. Public health model for prevention of liver cancer among Asian Americans. J Community Health. 2008;33(4): 199-205.

16. 2008 Population Estimates, US Census Bureau, Population Division. Available at http://factfinder.census.gov. Accessed December 14, 2009.

17. Taylor VM, Tu SP, Woodall E, et al. Hepatitis B knowledge and practices among Chinese immigrants to the United States. Asian Pac J Cancer Prev. 2006;7(2):313-7.

18. Lai CJ, Nguyen TT, Hwang J, Stewart SL, Kwan A, McPhee SJ. Provider knowledge and practice regarding hepatitis B screening in Chinese speaking patients. J Cancer Educ. 2007;22(1):37-41.

19. 2006-2008 American Community Survey, U.S. Census Bureau. Available at http://factfinder.census.gov. Accessed December 14, 2009.

20. Dornan T, Bundy C. What can experience add to early medical education? Consensus survey. Br Med J. 2004;329(7470):834-9. 
21. Diemers AD, Dolmans DH, Verwijnen MG, Heineman E, Scherpbier AJ. Students' opinions about the effects of preclinical patient contacts on their learning. Adv Health Sci Educ Theory Pract. 2008; 13:633-47.

22. Wear D, Zarconi J. Can compassion be taught? Let's ask our students. J Gen Intern Med. 2008;23(7):948-53.

23. Simpson SA, Long JA. Medical student-run health clinics: important contributors to patient care and medical education. J Gen Inter Med. 2007;22(3):352-6.

24. Weir RC, Tseng W, Yen IH, Caballero J. Primary health-care delivery gaps among medically underserved Asian American and Pacific Islander Populations. Public Health Rep. 2009;124(6):831-40.

25. Ponce NA, Hays RD, Cunningham WE. Linguistic disparities in health care access and health status among older adults. J Gen Intern Med. 2006;21(7):786-91.

26. Yeo SA. Language barriers and access to care. Annu Rev Nurs Res. 2004;22:59-76.

27. Ngo-Metzger Q, Massagli MP, Clarridge BR, Manocchia M, Davis RB, Iezzoni LI, Phillips RS. Linguistic and cultural barriers to care. J Gen Intern Med. 2003;18(1):44-52.

28. Chang ET, Nguyen BH, So SK. Attitudes toward hepatitis B and liver cancer prevention among Chinese Americans in the San Francisco Bay Area, California. Asian Pac J Cancer Prev. 2008;9(4):605-13.

29. Tran TT. Understanding cultural barriers in hepatitis B virus infection Cleve Clin J Med. 2009;76(Suppl 3):S10-3.

30. Lin SY, Chang ET, So SK. Why we should routinely screen Asian American adults for hepatitis B: a cross-sectional study of Asians in California. Hepatology. 46(4): 1034-40.

31. Hsu CE, Liu LC, Juon H, et al. Reducing liver cancer disparities: A community-based hepatitis B prevention program for Asian-American communities. J Natl Med Assoc. 2007;99(8):900-7.

32. Hsu LD, DeJong W, Hsia R, Chang M, Ryou M, Yeh E. Student leadership in public health advocacy: lessons learned from the hepatitis B initiative. Am J Public Health. 2003;93(8):1250-2.

33. Chang ET, Sue E, Zola J, So SK. 3 for life: a model pilot program to prevent hepatitis B virus infection and liver cancer in Asian and Pacific Islander Americans. Am J Health Promot. 2009;23(3):176-81.
34. Sellors J, Pickard L, Mahony JB, et al. Telephone reminders improved compliance with a second dose of hepatitis B vaccine in high risk adults. Evid-Based Nurs. 1998;1(44): 1136

35. Woloshin S, Schwartz LM, Katz SJ, Welch HG. Is language a barrier to the use of preventive services? J Gen Intern Med. 1997;12(8):472-7.

36. Pottie K. Misinterpretation: language proficiency, recent immigrants, and global health disparities. Can Fam Physician. 2007;53(11):1899-901.

37. Hu K. Hepatitis B Virus (HBV) infection in Asian and Pacific Islander Americans (APIAs): How can we do better for this special population? Am J Gastroenterol. 2008;103(7):1824-33.

38. Edmunds R. Increasing Access to Care with Diversity. J Dent Educ. 2006;70(9):918-20

39. Saha S, Taggart SM, Komaromy M, Bindman AB. Do patients choose physicians of their own race? Health Aff. 2000;19(4):76-83.

40. Saha S, Shipman S. Race-neutral versus race-conscious workforce policy to improve access to care. Health Aff. 2008;27(1):234-45.

41. Halliday-Boykins CA, Schoenwald SK, Letourneau EJ. Caregivertherapist ethnic similarity predicts youth outcomes from an empirically based treatment. J Consult Clin Psychol. 2005;73(5):808-18.

42. Finch J. Interprofessional education and teamworking: a view from the education providers. BMJ. 2000;321(7269):1138-40.

43. Kuehn AF. Collaborative health professional education: an interdisciplinary mandate for the third millennium. In: Sullivan TJ, ed. Collaboration: a health care imperative. New York: McGraw Hill; 1998:419-66

44. Morison S, Jenkins J. Sustained effects of interprofessional shared learning on student attitudes to communication and team working depend on shared learning opportunities on clinical placement as well as in the classroom. Med Teach. 2007;29(5):450-6.

45. Buchanan D, Witlen R. Balancing service and education: ethical management of student-run clinics. J Health Care Poor Underserved. 2006; 17(3):477-85

46. Beck E. The UCSD student-run free clinic project: Transdisciplinary health professional education. J Health Care Poor Underserved. 2005; 16(2):207-19.

47. Moskowitz D, Glasco J, Johnson B, Wang G. Students in the community: an interprofessional student-run free clinic. J Interprof Care. 2006:20(3):254-9. 